\title{
Etnozoología y Antropología
}

El objetivo principal de este artículo ${ }^{1}$ es llamar la atención sobre la etnozoología, disciplina con escasa presencia en la bibliografía antropológica española; aunque esto no impide, como veremos, que se hayan realizado estudios que conectan de una u otra forma con sus intereses. Trataremos de definir, en primer lugar, el sentido de la etnozoología en sí misma y en el marco de la llamada etnociencia; a continuación, repasaremos sus relaciones con disciplinas afines, como la antropología cognitiva, la etnozootecnia y la más lejana zootecnia. Asimismo, se recogerán las observaciones y críticas realizadas por algunos autores sobre las limitaciones de la etnozoología y los planteamientos de una antropología de la domesticación animal. Finalmente, intentaremos exponer cuáles son los elementos que puede aportar la etnozoología a la investigación antropológica en general.

En una segunda parte abordamos el ámbito español, comenzando con el comentario de algunos antecedentes nacionales sobre el estudio de "zoologías populares", de finales del siglo pasado y principios de éste, así como de etnografías de las culturas pastoriles. Más adelante se hace un breve repaso al papel jugado por los estudios del mundo animal en los escasos trabajos de carácter etnocientífico. Igualmente, dedicaremos algunas líneas a comentar el relativo auge de las investigaciones zootécnicas que, pese a no entrar apenas en el ámbito de la etnozootecnia y, menos aún, en el de la etnozoología propiamente dicha, pueden ser de gran ayuda para la antropología de la domesticación.

I

\section{ETNOZOOLOGIA, ETNOCIENCIA Y ETNOCIENCIAS}

En primer lugar, es evidente que los términos etnozoología y etnociencia tienen un carácter compuesto, por lo que deberíamos iniciar

\footnotetext{
1 Este trabajo fue redactado para su presentación en un curso de postgrado organizado por el Departamento de Antropología del Instituto de Filología del CSIC, celebrado entre los meses de febrero y marzo de 1992 y titulado -La antropología y las disciplinas sociales:. Posteriormente se han introducido algunas modificaciones.
} 
nuestro análisis definiendo los dos elementos que les dan forma. Comenzaremos por el final. Es obvio que la zoología es la ciencia o, mejor, el ámbito científico de la biología que estudia a los animales. Por su parte, el DRAE define la ciencia como el "conocimiento cierto de las cosas por sus principios y causas" y, también, como "cuerpo de doctrina metódicamente formado y ordenado, que constituye un ramo particular del humano saber. Desde este punto de partida, es el "etno" lo que da sentido propio a ambos términos, a etnozoología y a etnociencia. La tan socorrida partícula hace referencia, obviamente, al ámbito de la etnología como disciplina o, mejor aún, al del conocimiento etnológico (o antropológico); pero también al del objeto estudiado, calificado como "étnico" o "etnológicon por formar parte de los que se han considerado objetos de estudio más o menos clásicos de la etnología: los llamados pueblos primitivos y las comunidades campesinas de cualquier ámbito geográfico. De este modo, el objeto de estudio de la etnozoología sería una especie de "zoología étnican (igual que se emplea la denominación "música étnican), en la que se incluyen no sólo los conocimientos empíricos sobre el mundo animal sino también el corpus de creencias, imágenes y símbolos que en torno a ese mundo se genera en los diferentes grupos humanos. Sería, en definitiva, el conjunto de saberes que Machado y Núñez definió, a finales del pasado siglo, como la "historia natural popular" (aunque este concepto es más amplio), siguiendo en esto al francés Rolland; y lo que también los franceses, pero de hoy día, denominan "savoirs naturalistes populaires".

Con lo que acabamos de indicar, puede quedar definido el objeto de estudio de la etnozoología. Sin embargo, no podemos dejar de hacer notar que, tanto en este término como en el de etnociencia, se da una notoria contradicción en la esfera del objeto del conocimiento. Si una de las premisas de las etnociencias en general es que tienen por finalidad estudiar formas de conocimiento consideradas como no pertenecientes a la tradición científica, no parece muy correcto aplicar los términos etnociencia, etnozoología, etnobotánica, etc., a sistemas cognitivos ajenos a la ciencia en general y a la zoología, la botánica, etc., en particular. En este sentido, estamos de acuerdo -en parte- con J. Barrau (1988: 483), cuando afirma que hubiera sido más apropiado utilizar la terminología decimonónica empleada por Rolland, quien se refería a la ya citada "historia natural popular" como su objeto de estudio. Decimos "en parte" porque si se entiende la historia natural como disciplina $-\mathrm{y}$ no como objeto de estudio- estamos en la misma situación que si hablamos de etnociencia. Algo semejante ocurre con otros términos, como el de *zoología popular* empleado por el catalán Cels Gomis a principios de siglo. En realidad, los relegados conceptos originales de folklore, demología, demosofía, 
demótica $^{2}$, etc., poseen idéntico contenido, en cuanto a definición de objeto de estudio, que el de etnociencia, incluyendo por tanto a todas cuantas etnosubdisciplinas queramos nombrar, sin que caigan en la contradicción de calificar como científico lo que por definición no lo es.

Visto el objeto de estudio, queda delimitar a la etnozoología como disciplina. En cuanto tal, alguien podría considerarla sencillamente como una subárea de la antropología cognitiva, aunque en realidad aquélla surge mucho antes que esta última. Además, resulta obvio que la propia antropología cognitiva tiene sus orígenes en el desarrollo y ampliación de la reflexión etnocientífica. Sin embargo, por razones que veremos a continuación, los etnozoólogos no dudan en caracterizar con sentido propio su práctica científica, frente a la realizada desde la antropología cognitiva. Esta última resulta absolutamente constreñida por lo mental y alejada de lo material, más interesada en los procesos y formas de conocimiento que en el propio contenido de esos conocimientos. Su atención se dirige a las ideas, normas de comportamiento, categorizaciones de la realidad, principios organizativos..., no a las conductas, prácticas o instituciones materiales ${ }^{3}$. Para el etnozoólogo, sin embargo, su investigación no tiene como única finalidad, ni siquiera como principal objetivo, el estudio de las formas de conocimiento y clasificación nativas. Esto es sólo una parte de

2 A. Guichot y Sierra (1922: 237) señalaba una diferencia fundamental entre los términos demosofía y demótica. El primero hace referencia al objeto de estudio, a ta sabiduría del pueblo en sí misma, lo que el pueblo piensa, siente, quiere y hacen; el segundo define la disciplina, ula teoría que estudia esa sabiduría, estudia y compara el qué y el cómo de lo que el pueblo piensa, siente, quiere y hace.

3 M. J. Buxó (1980: 305 n.) también acepta la no similitud entre antropología cognitiva y etnociencia, pero con una argumentación frontalmente opuesta: "Aunque a menudo se usa de un modo sinónimo, la Antropología Cognitiva no es equiparable a Etnociencia o Etnosemántica. La Etnociencia hace referencia al conocimiento cultural, más que al comportamiento cultural, y a la vez, a aquella parte del conocimiento cultural que es accesible a través de la lengua de los informantes. Dentro de esta perspectiva etnosemántica se ha desarrollado la Etnoecología (...). En general, esta aproximación no considera las interacciones entre los dominios cognitivos y se restringe a las relaciones ecológicas intraculturales, así como propone un grado de homogeneidad y estabilidad en la categorización cultural. Por el contrario, en la Antropología Cognitiva son fundamentales las concepciones folk del ambiente en cuanto a su impacto en las concepciones, toma de decisiones y resolución de problemas relativos al comportamiento adaptativo y desadaptativo.

Ciertamente, compartimos por entero esta exposición sobre lo que debería ser la antropología cognitiva, pero consideramos que los reproches a la etnociencia cabe aplicarlos aún con mayor sentido a la práctica real de aquélla. Por otra parte, y como indicamos en el texto, el propósito de la etnozoología coincide en gran medida con el defendido por Buxó para la antropología cognitiva. 
su corpus científico, junto al cual se sitúan, a un mismo nivel, otros enfoques diferentes que hacen referencia a todo el complejo sistema de relaciones entre el hombre y el animal, desde su explotación económica hasta el mundo de representaciones simbólicas. Además, tan importante es para la etnozoología el análisis puramente emic de su objeto de estudio como la reflexión etic realizada desde la etnología y la zoología, aunque este último enfoque - el zoológico- no suele ser tan profundo como el anterior, dadas las generalizadas carencias en la formación en ciencias biológicas por parte del investigador. En definitiva, para la etnozoología no tiene sentido el dilema de si el estudio de la cultura - con la práctica etnográfica como etapa inicial- debe hacerse a partir de las categorías manejadas por el antropólogo o mediante el conocimiento de las propias categorías nativas: ambas perspectivas son necesarias y complementarias, no excluyentes ${ }^{4}$.

Para intentar aclarar algo más el sentido de toda esta discusión, vamos a ver cuáles han sido los orígenes históricos de la etnociencia y la etnozoología. Siguiendo a Barrau (1988), es evidente que para comprender este proceso sería necesario repasar la historia de la toma en consideración científica del estudio de las relaciones entre los hombres, su medio ambiente natural y los recursos de éste. Hasta el siglo XVIII, la llamada "historia natural. incluía en su ámbito de estudio al hombre. Posteriormente, éste sería excluido, al tiempo que pasaron a ser considerados ridículos y fuera de todo interés los saberes naturalistas populares. Este proceso conduce, asimismo, al avance creciente de la especialización en ámbitos del conocimiento cada vez más concretos y limitados. Como reacción de algunos sectores científicos a la superespecialización, surgen planteamientos como los de Haeckel y su "ecología", Engels y su "dialéctica de la naturaleza", E. Reclus y su "hombre y la tierra", Ratzel y su "antropogeografía", etc., que intentan recuperar el estudio del hombre y las sociedades en el seno de

\footnotetext{
4 No podemos entrar a valorar la etnociencia como modelo teórico de investigación antropológica, aunque en el texto se comentan algunas de sus limitaciones, apuntando sobre todo hacia la antropologia cognitiva. Lo mismo cabría señalar en relación con la pretendida revolución que supone la enueva etnografia. en cuanto a la orientación del propio estudio etnográfico, primando la visión emic frente a la etic. Estas y otras cuestiones relacionadas con la etnociencia fueron duramente criticadas por Marvin Harris (1978: 491-523) y, de forma más matizada, por otros muchos autores (cfr. Fowler, 1979: 235-238; Kaplan y Manners, 1979: 300-311). En esta última obra citada se hace referencia, asimismo, a algunas contrarréplicas escritas por representantes de la "nueva etnografía. Un debate más reciente y equilibrado sobre lo emic y lo etic puede verse en Headland, Pike y el mismo Harris (1990). En España, G. Bueno (1990) ha estudiado de forma detallada la obra de Pike, el definidor de las categorías emic y etic.
} 
la naturaleza ${ }^{5}$. En los EEUU, en 1895 , el botánico J. W. Harshberger utiliza por vez primera el término «etnobotánica». El objetivo de este autor era estudiar los vegetales y productos vegetales empleados por las sociedades "arcaicas* o "primitivas", definir la distribución antigua de estas plantas, intercambios, etc., todo con una clara óptica difusionista y con el fin de determinar la "posición cultural de las tribus". El estudio tiene por tanto una clara posición externa ${ }^{6}$. Este tipo de trabajos interesará muy especialmente al Bureau of American Ethnology, dos de cuyos miembros utilizan por vez primera, en 1914, el término etnozoología: J. Henderson y P. J. Harrington, en su obra Ethnozoology of the Tewa Indians. En estos autores sí aparece definido ya con claridad lo que luego será la base de la "nueva etnografía: el interés por estudiar el discurso local de las culturas sobre la naturaleza.

Como recuerdan varios autores (Berthe-Friedberg, 1991; Barrau, 1985), el término "etnociencia" fue utilizado por vez primera por G. P. Murdok, en el índice de su Outline of cultural material, para designar (dentro de su Human Relation Area Files) la sección 82 que se titula "Ideas acerca de la naturaleza y el hombre y que, según él, estaba destinada a recoger alas nociones especulativas y populares acerca de los fenómenos del mundo externo y del organismo humanon. En dicha sección, bajo el título de etnociencia, se reúnen ámbitos como etnoanatomía, etnobotánica, etnometeorología, etnozoología, etc.

Pero será la llamada "nueva etnografía norteamericana la que dé a la etnociencia su empuje definitivo, debido a su interés por establecer analogías entre código lingüístico y código cultural, intentando reconstruir cada cultura a partir de la suma de las clasificaciones populares aplicadas a todos los dominios (Sturtevant, 1964). Suele considerarse a W. Goodenough el fundador del análisis etnocientífico y, por extensión, de la antropología cognitiva, tomándose como punto de partida su artículo de 1956 sobre “Componential Analysis" (Applebaum, 1987: 406; Goodenough, 1974). El objetivo era analizar las categorías nativas de pensamiento, pues la cultura solamente se encuentra en la mente de los individuos, en ese -mapa cultural. en el que se recoge todo lo que deben saber para desenvolverse satisfactoriamente en la sociedad. Otro representante de esta "nueva etnografía", H. Conklin, puso especial énfasis en destacar que la etnociencia parte de las categorías semánticas indígenas para estudiar el

5 Todo ello sin citar los estudios precursores de economía ecológica del siglo XIX que de forma tan acertada estudia Joan Martínez Alier (1991).

6 Algunos años antes, en 1889, Robert E. C. Stearns había publicado en Washington un trabajo titulado Etbno-concbology. A study of primitive money, en el marco de la Smithsonian Institution (Pujol y Carbone, 1991: 1311). 
conocimiento que una sociedad tiene de su entorno. En este sentido, las influencias del lingüista Noam Chomsky han resultado fundamentales en el desarrollo -y también en las limitaciones- de la etnociencia y, en definitiva, de la antropología cognitiva. Desde esta perspectiva, no puede extrañar que Sturtevant (1964) definiera la cultura como "la manera particular que tiene una sociedad para clasificar, principalmente por el lenguaje, su universo material y social.

Esta visión mentalista de la cultura, y del análisis antropológico de la misma, no puede ser compartida sin más desde la etnozoología. Más arriba lo hemos indicado en relación con la antropología cognitiva, pero igualmente podríamos haber escrito etnociencia, pues es a partir de ella desde donde se establece el modelo teórico de análisis que hace suyo la antropología cognitiva. Por tanto, si es cierto que la etnociencia y la "nueva etnografía aportan indudables elementos positivos a la etnozoología, también lo es que no alcanzan a cubrir los intereses de esta última. No obstante, y como veremos más adelante, todavía hoy se reclama y emplea el término etnociencia desde el entorno de la etnozoología, aunque bien es cierto que su contenido semántico ha sido modificado.

Continuando con el repaso histórico sobre la reflexión etnocientífica, observamos que en Francia no se utilizan estos términos (en concreto el de etnobotánica) hasta los años cuarenta, aunque hay precedentes de estudios con carácter semejante, como el que en 1903 publicaron Durkheim y Mauss en L'année sociologique titulado "De quelques formes primitives de classification. Contribution à l'étude des représentations collectives». Aunque en 1942 lo había usado el haitiano Jacques Roumain, será en 1943 cuando se emplee con todo su alcance el término etnobotánica, en la importante obra sobre L'bomme et les plantes cultivées de André-Georges Haudricourt y Louis Hédin. Al primero se debe, igualmente, la introducción en Francia del término etnozoología en 1962. En ese mismo año se publica una obra fundamental en el seno de la etnociencia, La pensée sauvage de Lévi-Strauss. Por lo que respecta al ámbito institucional, el desarrollo de estas investigaciones partirá del Museo Nacional de Historia Natural donde, en 1963, Roland Portères crea el Laboratorio de Etnobotánica, ampliado en 1966 a la etnozoología en su contenido y denominación.

Como ya hemos indicado, el término etnociencia se ha continuado utilizando pese a sus defectos o, mejor, pese a su deficiente concepción, aunque en los últimos años ha sufrido un significativo proceso de reelaboración de contenidos. El sentido en que emplean este término la mayor parte de los estudiosos de los "saberes naturalistas populares" coincide en gran medida con los que se exponen a continuación. Para 
Berthe-Friedberg (1991: 254), la etnociencia conjuga dos tipos de análisis: de un lado se abordan las categorías y los conceptos implícitos desde el punto de vista de quienes los utilizan; de otro, se estudian idénticos objetos y fenómenos desde las categorías o los conceptos científicos. Se puede hablar por tanto de análisis "interior" y análisis "exterior", distinción que prefiere a la de etic y emic. El conocimiento de estos saberes puede enfocarse hacia la búsqueda de una estructura universal común, pero quizás esté más extendido considerar estos saberes y las representaciones simbólicas como reveladores de una estructura social particular, en la que los fenómenos de identidad tienen mucho que decir.

Christian Bromberger (1986) define las etnociencias -en cuanto objeto de estudio- como los procedimientos de conocimiento y clasificación indígenas del mundo material y social. Establece que su dominio se sitúa entre los límites de la etnología, las ciencias naturales y la lingüística. Señala que fue en los años cincuenta cuando el análisis exterior del funcionamiento de las sociedades y las culturas se fue sustituyendo progresivamente por una etnología de lo interior, tendente a definir cómo los hombres clasifican, ordenan, perciben y utilizan el mundo que les rodea. Advierte, no obstante, que en estas clasificaciones indígenas entran en funcionamiento diferentes lógicas clasificatorias: de identificación (que clasifica en función de criterios morfológicos, por ejemplo); de uso culturalmente definido (p.ej., según sus propiedades funcionales); y simbólicas. Además, se ha de tener precaución y no pensar que existe siempre un campo perfectamente autónomo de conocimiento del medio natural en todas las culturas, al igual que existe en el mundo científico. Recuerda, igualmente, que un ámbito de estudio menos tratado, pero que también entra de lleno en el análisis etnocientífico, es el que engloba los diferentes registros sensoriales que permiten a los individuos la aprehensión del medio que les rodea. Otra cuestión a tener en cuenta es que debemos interrogarnos sobre los modos de transmisión de estos saberes, su jerarquización social, etc. Asimismo, se han de considerar las relaciones entre los modos de conocimiento del mundo y la práctica real sobre éste. El actual interés por los saberes naturalistas populares radica, según el autor, en las dificultades mostradas por nuestra sociedad en las relaciones entre naturaleza y cultura: crisis de la relación con el medio ambiente, crisis del conocimiento positivista, crisis de la transmisión unilateral de los saberes y reconocimiento de la pluralidad de procedimientos cognitivos, etc.

En cuanto al modelo de acercamiento en la investigación etnozoológica, Barrau no cree que deba ser subordinado el saber naturalista local al saber científico. El objetivo final de la etnociencia es *aprehender los 
sistemas de ideas, las nociones y actitudes que una sociedad desarrolla en relación con los hechos, los objetos y fenómenos de su entorno, sistemas que son igualmente códigos de comportamiento que se expresan en la lengua, en el discurso de esa sociedad. (1985: 9). Esto no es obstáculo para afirmar que una aptitud o formación naturalista (como la de Haudricourt, Concklin, etc.) facilita la investigación: es difícil que alguien que no conozca su propio medio natural, aunque sea superficialmente, sepa adentrarse en las formas de conocer el medio de otras sociedades. La interrelación entre ciencias humanas y naturales resulta imprescindible. Por otra parte, Barrau advierte sobre una peligrosa especialización en etnolo que sean, pues no se debe olvidar que las sociedades se relacionan con su medio ambiente de una forma compleja y unitaria. Finalmente, el autor señala que quizás sería mejor emplear la expresión "historia natural popular" en lugar de las "etnos", volviendo a unos orígenes en los que la historia natural, como ya se ha dicho, no disociaba al hombre en el conjunto de la naturaleza.

El renacer de los estudios etnozoológicos en la década de los ochenta hace suyos los planteamientos de los autores franceses que acabamos de citar $^{7}$. No obstante, junto a la asepsia de la investigación realizada con el único objetivo de conocer y explicar las diferentes culturas, se extiende la vertiente aplicada de estos estudios. Nuevamente debemos volver al ámbito francés para encontrar los ejemplos más cercanos en el espacio y lejanos en el intelecto de este tipo de aplicaciones. Desde los años setenta se desarrollan programas interdisciplinares que asocian ciencias humanas y ciencias naturales para el estudio de las relaciones hombre-medio ambiente. En los años ochenta los nuevos proyectos se articulan en torno a los parques naturales nacionales y regionales, y tienen como objetivo común la investigación sobre los "saberes naturalistas populares". Algunos proyectos se limitan a inventariar especies vegetales cultivadas, plantas medicinales, etc., con el fin de, por ejemplo, reactivar economías agrícolas en declive. Otros inciden más de lleno en la relación entre los saberes naturalistas y las formas de organización económica y social, interesándose también en los sistemas de transmisión de los conocimientos. Una de las aplicaciones más comunes, que relaciona etnozoología y etnozootecnia, es el conocimiento de las técnicas de explotación y pastoreo de razas autóctonas de ganado, que persigue la conservación de un patrimonio

\footnotetext{
Aunque resulta una opción discutible, no vamos a comentar aquí la obra de varios autores que trabajan en el ámbito de la antropología simbólica y que han realizado importantes aportaciones - desde ese contexto- a la etnología. Nos referimos especialmente a P. Bouissac (1972), D. Sperber (1975) y M. Albert-Llorca $(1991,1993)$.
} 
genético animal en peligro de desaparición, a través del estudio de las peculiares estrategias ecológicas y económicas que explican la propia existencia de dichas razas y las causas de su decadencia.

\section{ETNOZOOLOGIA, ZOOTECNIA Y ETNOZOOTECNIA}

Conectando directamente con la vertiente aplicada que acabamos de señalar, vamos a presentar ahora muy brevemente las relaciones existentes entre etnozoología, zootecnia y etnozootecnia. Comenzaremos nuevamente por las definiciones. Con el término zootecnia se designa a la disciplina o subdisciplina científica que tiene por objeto mejorar la cría y explotación de los animales útiles al hombre. Surge como tal a mediados del siglo pasado, siendo un veterinario francés, A. de Gasparin, quien, al parecer, utilizó por vez primera el término en su obra Cours d'agriculture de 1844 (Théret, 1988: 1252). Ese mismo año y en España, el catedrático de Veterinaria Nicolás Casas (autor de un ingente número de obras sobre agricultura y ganadería) empleaba, con idéntico sentido, los términos economía rural, "zoonomología doméstica* y "zoologiculturan (Casas, 1844: I, 2). Este autor se hizo eco rápidamente de la nueva denominación disciplinar, consiguiendo introducir la enseñanza de la zootecnia en la Escuela Superior de Veterinaria en 1847, aunque no como asignatura oficial. El mismo Casas, en su Diccionario de agricultura y ganadería españolas (1857: IV, 376-377), dice lo siguiente:

La zootechnia debe ser el complemento de las ciencias naturales, sobre todo de la zoología, en lo que tiene de aplicable a la producción animal de cualquier naturaleza, a las locomotivas vivas, empleadas para la explotación de las tierras, para el comercio, la industria, el ejército, aclimatación; etc., etc. Para apoyar la opinión que acabamos de emitir sobre la zootechnia, basta recordar el uso que hacemos de los animales reducidos a la domesticidad. En efecto, un animal doméstico, que sea de renta o de trabajo, no se le debe ni puede considerar mas que como una máquina viva, compuesta de aparatos mecánicos y químicos, multiplicados y variados, fabricando, con el alimento que se le da, todos los productos animales, utilizados para nuestras subsistencias, nuestras necesidades (...).

El éxito de la nueva denominación fue rotundo, manteniéndose hasta la actualidad. Aunque su sentido es esencialmente económico y ajeno, en principio, a cualquier tipo de análisis cultural, lo cierto es que etnólogos y etnozoólogos tienen en los estudios de esta disciplina una fuente de conocimientos imprescindible para abordar desde una base científica lo que podríamos denominar como zootecnia popular. Por su parte, la 
misma zootecnia puede encontrar interesantes aportaciones tomadas de las prácticas tradicionales de crianza y explotación del ganado. Precisamente para incrementar este interés por los aspectos sociales y culturales (tradicionales o modernos) de la producción animal, surgió en Francia, otra vez, a comienzos de los años sesenta, una nueva disciplina, la etnozootecnia, apoyada por una sociedad científica y un boletín del mismo nombre. Esta publicación (Etbnozootechnie) ha logrado reunir, y sigue haciéndolo, muy interesantes estudios que conectan directamente la zootecnia y la etnología, con números monográficos de títulos tan sugerentes y variados como: Le Yak. Son rôle dans la vie matérielle et culturelle des éleveurs d'Asie centrale; L'Ethnozootechnie. Ses relations avec les sciences; Les concours de bétail; L'evolution de l'élevage domestique; Evolution des rapports hommesanimaux en milieu rural, etc.

Sin embargo, pese a estos interesantes planteamientos, el antropólogo francés J.-P. Digard (1991: 58) considera que la etnozootecnia no ha conseguido los resultados esperados, ya que

(...) l'ethnozootechnie reste dominée par les préoccupations des agronomes, vétérinaires et autres practiciens de l'élevage, pour qui la dimension ethnologique de la domestication animal se réduit trop souvent à un folklore désuet; elle est en outre confinée en des lieux (institutions proches des écoles vétérinaires, des instituts agronomiques, des haras, etc., placés sous la tutelle du ministère de l'Agriculture) où les problématiques scientifiques son entièrement dictées par les sollicitations des milieux professionnels de l'élevage, de l'agro-alimentaire, bref du marché.

Por todas estas razones, Digard opina que la etnozootecnia "no está en condiciones de responder a las cuestiones que la antropología se plantea en relación con la naturaleza del acto de la domesticación, sobre sus determinantes y sus implicaciones técnicas, sociales e ideológicas" (id.).

\section{Situación de la ETNOZOOlOGÍa EN EL CONTEXTO DE LA INVESTIGACIÓN ANTROPOLÓGICA}

La situación actual de la etnozoología como disciplina con un objeto de estudio y una metodología específicas es un tanto ambigua. Por una parte, los conceptos de etnociencia e investigación etnocientífica han quedado prácticamente subsumidos en el de antropología cognitiva. Esto supone que se ha avanzado mucho más allá de los límites originales de las diferentes disciplinas etnocientíficas en cuanto al estudio de las formas, modos y sistemas de conocimiento y clasificación de las diferentes culturas. Pero, junto a este hecho constatable, es evidente también que la antro- 
pología cognitiva se ha desentendido totalmente del propio contenido de esos conocimientos, vistos en su doble perspectiva de corpus de ideas y de conjunto sistematizado de prácticas y técnicas de manipulación del entorno natural y social. Esta situación ha conducido a una falta de conexión, cuando no rechazo, entre antropología cognitiva y etnozoología.

También es evidente la falta de interés por la etnozoología de muchos de quienes se autocalifican como etnólogos o antropólogos y estudian sociedades cazadoras, agricultoras o pastoriles. En general, la atención prestada por estos autores a los animales se reduce, como apunta Digard, a unas breves páginas introductorias sobre sus rasgos físicos, dedicando el conjunto de su investigación a la organización económica y social. Por su parte, desde algunas otras obras de antropología ecológica y económica se plantea un estudio más intenso de la relación hombre-animal, pero también aquí los intereses suelen estar muy centrados en modos de subsistencia y factores de producción, arrinconando otros ámbitos de esa relación, sobre todo el mundo de las representaciones simbólicas.

Después de lo dicho, ¿quién reivindica y practica la etnozoología? Sin lugar a dudas, es en Francia donde más se emplea hoy esta expresión para definir un ámbito concreto de investigación con una metodología también propia. Es cierto que existe una muy importante corriente investigadora americana y británica sobre el estudio de las relaciones hombre-animal, pero durante los tres últimos lustros se vive en Francia un auténtico apogeo de los estudios etnozoológicos, potenciado por investigadores provenientes tanto de la zoología como de la etnología. No obstante, hay voces en el mismo ámbito francés que cuestionan la validez general del enfoque etnozoológico. Digard es el máximo exponente de esta perspectiva, pues considera que dicha disciplina está condicionada por el hecho de prestar especial atención al mundo de los signos, sobre todo en relación con los animales salvajes, habiendo dejado de lado a los domésticos, cuyo estudio ha sido abordado por la etnozootecnia, con las limitaciones que él mismo ha apuntado. Habiendo repasado diferentes bibliografías y leído algunas obras, nos parece que la valoración de Digard no es del todo correcta. Este autor reivindica un nuevo planteamiento en la relación hombre-animal, una santropología de la domesticación. que una en un mismo sistema de investigación slos animales, su domesticación y la 'morfología' de las sociedades que la practican" (1991: 80). Los estudios a realizar desde esta perspectiva deben considerar que: 1) la domesticación es una acción continua, renovada día a día, no un proceso histórico localizable en el tiempo y el espacio; 2) plantearse la noción de domesticación desde una acepción amplia que recoja todas las actividades de producción y utilización de los animales domésticos; 3) no despreciar las 
formas marginales de la domesticación; 4) ser totalizantes y pluridisciplinarios; 5) guardarse tanto de la excesiva dependencia como de la indiferencia total en cuanto a la preocupación por los fines de la investigación (ibid.: 81). Para poder abordar de forma ordenada este vasto proyecto, Digard propone varias etapas: 41) inventario crítico de especies animales domesticadas y tipos de domesticación; 2) estudio de las formas de 'consumo' (en su significado más amplio) y de los medios de producción de los animales domésticos; 3 ) análisis de las relaciones existentes entre la domesticación y la organización de las sociedades y sus sistemas de pensamiento" (id.).

Los planteamientos de Digard son ciertamente interesantes, y su obra L'bomme et les animaux domestiques supone un importante avance en el estudio de las relaciones hombre-animal. Sin embargo, su crítica sobre un hipotético reduccionismo de la etnozoología puede ser aplicada también a su propia investigación. Aunque la noción de domesticación que emplea es lo suficientemente amplia y compleja para abarcar una amplia variedad de relaciones hombre-animal, lo cierto es que restringe el ámbito de estudio, excluyendo todo lo que no entre de una u otra forma en la esfera de la domesticidad. Desde esta perspectiva, quedarían al margen de la investigación la gran mayoría de las sociedades cazadoras (aunque algunas formas de caza podrían ponerse en contacto con un incipiente proceso de domesticación) y los complejos sistemas de relaciones que se establecen entre cazadores y sus presas.

Pero si Digard reivindica una antropología de la domesticación frente a la etnozoología, en otros ámbitos se abordan temas idénticos a los estudiados desde estas dos subdisciplinas sin tan siquiera nombrarlas. Esto es especialmente evidente en el contexto anglosajón. En Gran Bretaña existe una gran tradición en el estudio de las relaciones hombre-animal, desde muy variadas perspectivas. En los últimos años destaca la obra de autores como Tim Ingold, que ha trabajado, por ejemplo, con sociedades como las de los pastores-cazadores de renos del norte de Europa (1988) y ha escrito sobre diferentes temas relacionados con grupos humanos y animales (1986 y 1994, entre otros muchos). Ni T. Ingold ni otros autores emplean en sus investigaciones los términos etnozoología o etnociencia, sino los de antropología ecológica o ecología humana. Sin embargo, no limitan su actividad al ámbito de la apropiación de la naturaleza por parte del hombre. Un buen ejemplo de cómo se plantea el estudio de las relaciones hombre-animal en el ámbito anglosajón lo tenemos en la denominación y contenido de uno de los temas principales discutidos en el Congreso Arqueológico Mundial celebrado en Southampton (Inglaterra), en septiembre de 1986, titulado .Cultural Attitudes to Animals, including Birds, 
Fish and Invertebrates". Los cuatro ámbitos en los que se estructuró dicho symposium reflejan toda la complejidad de las diferentes actitudes culturales que manifestamos frente a los animales. El primero de dichos ámbitos estuvo al cuidado de Tim Ingold y llevaba por título What is an animal? (Ingold, 1987); el segundo abordaba el tema de The Appropiation, Domination and Exploitation of Animals (Clutton-Brock, 1989); en el tercero se discutió sobre Semantics of Animal Symbolism (Willis, 1990); y en el cuarto, por último, sobre Learnig from Art about the Cultural Relationships between Humans and Animals (Morphy, 1989). Es difícil pensar en cuestión alguna en la relación hombre-animal que no quede incluida en alguno de estos cuatro apartados, que condensan el sentido y objeto de la etnozoología; sin embargo, en ningún momento se emplea este término. El objeto de estudio lo comparten, en una marcada interdisciplinariedad, la antropología social y cultural, la historia, la psicología, la etología, la arqueozoología...

Por nuestra parte, consideramos que la etnozoología debe tener un sentido propio en el seno de las disciplinas etnológicas, aunque sin cerrarse en sí misma, pues se trata únicamente de un ámbito de investigación en un conjunto más amplio. Entre sus objetơs de estudio, los relacionados con la domesticación animal tienen una especial importancia, como demuestran los debates habidos sobre el propio concepto de domesticación y la amplia reflexión llevada a cabo por Digard, pero lo salvaje no debe ser desatendido. No creemos aventurado afirmar que la etnozoología ha de encontrar su lugar relacionándose directamente tanto con la antropología cognitiva como con las antropologías económica y ecológica. Todo ello sin olvidar que en la fundación de la "nueva etnografia" $-\mathrm{y}$, por tanto, en estrecha ligazón con la etnozoología - tuvo especial relevancia la reflexión sobre la validez del análisis etnográfico y la racionalidad y legitimidad de la traducción cultural que supone ${ }^{8}$, debate que aún continúa latente.

\section{Estudios afines a la inVestigación etNOZOOlÓgica En España}

Por el título dado a este apartado se deduce que consideramos que no ha existido ni existe en España una investigación etnozoológica, en el

8 Reflexión retomada recientemente, desde una óptica algo diferente, por los antropólogos postmodernistas californianos Clifford y Marcus (1991 [1986]). 
sentido estricto del término. Sin embargo, sí se ha publicado un buen número de obras que, de una forma u otra, comparten algunos de los intereses de la etnozoología moderna. Al mismo tiempo, hay antecedentes de esta orientación investigadora en el siglo XIX y primeras décadas del $\mathrm{xx}$, y a ellos es precisamente a los que nos vamos a referir en primer lugar.

Partimos de la segunda mitad del siglo pasado y más concretamente de la ciencia del folklore que entonces nace. Dejamos pues a un lado cualquier otro tipo de estudio o reflexión acerca de la relación hombreanimal, que sin duda ha existido, desarrollado en momentos anteriores. En 1882 A. Machado y Núñez (el padre del folklorista Machado y Álvarez y abuelo de los poetas) publica en El Folk-Lore Andaluz un breve artículo (inconcluso) sobre "El Folk-Lore del perro", muy significativo del tipo de estudios que se planteaban entonces, más bien fuera que dentro de nuestras fronteras. La influencia más directa era sin duda la del francés Eugène Rolland, que en 1881 concluía la publicación de su extenso estudio sobre zoología popular francesa, cuya aparición fue comentada en las páginas de la misma revista por A. Machado y Álvarez. La perspectiva teórica desde la que trabaja Machado y Núnez queda perfectamente recogida en la siguiente cita:

La idea del Folk-Lore o de los saberes populares, en su relación con el hombre y los animales, va adquiriendo tal incremento entre los hombres más eminentes de Europa, que no dudamos constituirá en breve una nueva ciencia que amplie y perfeccione los conocimientos adquiridos hasta hoy por la Historia Natural. (...)

Bajo tres diversos prismas, a cuál más interesante, podemos considerar el FolkLore de los animales.

1. Para perfeccionar la historia zoológica del individuo que analizamos.

2. Para conocer el sentido mitológico y fantástico de las creencias y preocupaciones del vulgo, que influyen sobre la imaginación de las gentes más o menos ilustradas.

3..$^{\circ}$ Bajo el aspecto filológico, que nos hace remontar el origen de las lenguas e idiomas primitivos y poder apreciar el valor onomatópico e ideológico de los sonidos, voces o palabras con que se designan aquellos seres.

Solamente estas tres maneras de considerar la idea del Folk-Lore o saber del pueblo convienen por hoy a nuestro propósito en el objeto que motiva este artículo, que es únicamente expresar lo que independientemente de la Ciencia piensa y gráficamente dice el pueblo acerca de uno de los animales más numerosos y adheridos al hombre desde la más remota antigüedad (Machado y Núnez, 1882: 24).

Dado que el estudio está sin concluir, Machado no tiene tiempo sino de hacer alguna observación acerca de la domesticidad del perro, las enfrentadas consideraciones que sobre el mismo tienen diferentes grupos 
humanos, su presencia en refranes y mitos clásicos y orientales y sobre la importante ayuda que presta a los pastores. Es obvio que el autor pone especial énfasis en reseñar la presencia de este animal en la literatura oral, pero sus breves citas al ámbito práctico de la "explotación" del perro evidencian - junto con su formación y profesión como naturalista- que su concepto de la "historia natural popular" coincide en gran parte con el objeto de estudio de la etnozoología. Como el propio autor indica, la ciencia del folklore recogía, como un apartado más de su amplio plan de trabajo, el estudio de estos conocimientos y saberes populares, aunque en la práctica nunca se llevaron a cabo en España investigaciones de carácter semejante a la propuesta por Machado y Núñez, ni en su época ni en etapas posteriores.

Con todo, sí existen aportaciones, muy interesantes algunas, que se plantean el estudio de la relación hombre-animal desde una óptica que escapa a las ataduras de las más clásicas etnografías de lo pastoril, que serán las que prevalezcan sin lugar a dudas. En ambos campos, y durante la primera mitad del siglo $\mathrm{xx}$, destacan de forma palpable en España los estudios de autores catalanes. Veamos en primer lugar las obras menos encorsetadas en la etnografía pastoril.

Debemos comenzar citando a Cels Gomis, que publica en $1910 \mathrm{su}$ Zoologia popular catalana, y que también escribe sobre agricultura, botánica y meteorología populares. Según Ll. Prats (s.f.: 79), Gomis *abrió una vía de aproximación a la cultura popular hasta entonces inédita en Cataluña; se trata de lo que ahora llamaríamos etnociencia o conocimiento popular del medio". Esta idea es aceptable sólo en parte, dadas las limitaciones de la obra de Gomis. Ciertamente, sus trabajos destacan tanto por su temática como por la minuciosidad en la recogida documental; sin embargo, el autor no se preocupa por avanzar en la metodología y no realiza estudio complementario alguno.

En 1918, D. Danés i Torras y J. Carreras i Artau publican un interesante cuestionario sobre "Costums i tractes més usuals referents a bestiar", dentro del conjunto de las actividades desarrolladas en el seno del Arxiu d'Etnografia i Folklore de Catalunya creado y dirigido por Tomás Carreras. Ciertamente, el ámbito del ganado y los animales había sido tratado ya en cuestionarios generales, pero debido a ello la profundización en el tema había sido siempre escasa. El trabajo de Danés y Carreras es, asimismo, limitado pues, como queda dicho, trata de recoger información sobre tratos y contratos. No obstante, el cuestionario incluye también preguntas sobre pastoreo, alimentación, enfermedades, nombres del ganado, creencias y supersticiones, etc. En los fondos del Arxiu se conservan 55 respuestas y materiales diversos relacionados con este cuestionario (Calvo, 1990: 51-63). 
En una línea menos etnográfica que la mantenida por los investigadores del Arxiu y más entroncada con el estudio del habla, las creencias y las supersticiones, se encuentran los diversos trabajos que sobre el mundo animal y lo popular publica Joan Amades, de carácter eminentemente folklorista.

Retornando al ámbito de la etnografía, debemos concluir, por el momento, esta relación de autores catalanes con la que consideramos su principal figura y una de las más importantes del Estado: Ramon Violant i Simorra. Pese a su temprana muerte, Violant dejó una impresionante obra, en la que el estudio de la cultura pastoril y en general de la relación del hombre con los animales domésticos tiene una especial relevancia. Con la profundidad y el detalle característicos de toda su obra, Violant escribió sobre abejas y colmenas, la matanza del cerdo, enfermedades y marcas del ganado ovino, trashumancia, supersticiones relacionadas con el color de los animales, pastoreo, etc. Sin lugar a dudas se trata del autor que con mayor sensibilidad y espíritu científico ha estudiado buena parte de la temática que puede englobarse en una investigación etnozoológica.

Pero, obviamente, no sólo ha habido autores catalanes que han analizado desde la etnología o el folklore el ámbito de las culturas pastoriles y las representaciones simbólicas del mundo animal. Otro foco interesante ha sido el desarrollado en el País Vasco, orientado esencialmente hacia estudios etnográficos del pastoreo y con el Anuario de Eusko-Folklore como principal órgano de difusión de sus investigaciones. Sobre este tema han escrito J. Arín Dorronsoro. J. M. de Barandiarán, F. de Leizaola, etc. Asimismo, en diversas monografías y en artículos aparecidos en los Cuadernos de Etnologia y Etnografia de Navarra, se han publicado estudios etnográficos sobre poblaciones vascas y navarras en las que se estudian los ámbitos de la ganadería y el pastoreo siguiendo al pie de la letra el cuestionario de J. M. de Barandiarán.

Además de vascos y catalanes, muy diversos autores realizan estudios etnográficos sobre culturas pastoriles. Aunque hay un buen número de contribuciones más o menos extensas e interesantes, es indudable que debemos destacar la labor pionera de Joaquín Costa, que nos permite disponer hoy día de un amplio y valioso conjunto de estudios sobre costumbres de economía y derecho populares, un buen número de ellos dedicados al conocimiento de los usos y costumbres relacionados con el ganado. Todo ello a través de sus investigaciones personales y de la dirección de proyectos colectivos, plasmados tanto en la redacción de obras conjuntas como en otro tipo de empresas. Entre estas últimas hay que destacar los concursos que sobre "Derecho consuetudinario y economía popular" organizó, a propuesta y con programa de Costa, la Real Academia de Ciencias Morales y Políticas entre 1898 y 1918. 
Menos interesados que Costa y sus colaboradores por la economía, los contratos y el derecho consuetudinario, y más centrados en técnicas de pastoreo, se encuentran otros estudios de etnografía pastoril escritos ya después de la guerra. Además del citado Violant, los de mayor interés son seguramente los detallados trabajos de L. Cortés Vázquez sobre el ámbito salmantino, que abarcan desde el estudio de la cultura material del pastor hasta la descripción de remedios frente a las enfermedades del ganado, nombres de los animales, etc.

Un carácter distinto al de los más o menos clásicos estudios sobre etnografía pastoril tienen los trabajos que desde los años veinte a los sesenta publica J. Uría Ríu acerca de los vaqueiros de alzada de Asturias, ya que resultan menos descriptivos y más interesados por problemas relacionados con aspectos históricos y sociales. No obstante, en todos ellos aparece la vaca como referente inevitable de la cultura vaqueira.

Un capítulo aparte dentro de las descripciones etnográficas es el que conforman los estudios sobre la matanza del cerdo, bastante numerosos pero no todos con la profundidad necesaria (Álvarez, 1986; Cofradía, 1991; Fidalgo, 1985; Manso, 1990; Santos y Sanz, 1988; Barandiarán y Manterola, 1990).

Otro ámbito de interés es el que hace referencia al estudio de creencias, supersticiones, literatura oral y folklore. En obras generales de esta temática suelen aparecer referencias al mundo animal, salvaje o doméstico, pero los trabajos dedicados de forma específica a este ámbito son muy escasos. Podemos citar, por ejemplo, el estudio de F. Bouza sobre tradiciones acerca del lagarto en Galicia, el de L. Castañón sobre folklore de la vaca en Asturias y los de L. Prieto sobre algunos animales domésticos y salvajes en La Gudiña y la "zoantropía" en Galicia. En este tipo de trabajos el animal o animales tomados como referencia suelen ser únicamente el pretexto para acotar un conjunto de creencias o tradiciones, sin que exista un auténtico interés por la relación hombreanimal.

Las monografías y estudios de comunidad son otra esfera en la que se pueden encontrar referencias escuetas al mundo animal. Los datos suelen ser escasos, limitándose a apuntar algunos aspectos de la economía ganadera del núcleo en cuestión o a señalar algunas prácticas pastoriles; a veces, ni eso. En los antropólogos sociales el interés por el tema es escaso; los etnógrafos le dedican algunas, pocas, páginas más. En uno y otro caso no hay excepciones. Sólo algunas monografías conectadas con la antropología ecológica destacan algo más el papel del ganado en el sistema social (López Linage, 1978). Recientemente se ha publicado en inglés la tesis doctoral de W. Kavannag (1994) -que no hemos podido 
consultar, aunque sí conocemos otros trabajos del autor-, sobre una comunidad de ganaderos trashumantes de la Sierra de Gredos, en la que también se podrá ver alguna referencia al estudio de las relaciones hombre-animal.

Desde otras disciplinas se han realizado aportaciones sobre las actividades ganaderas y pastoriles, mucho más interesantes la mayoría que las escritas desde el folklore, la etnografía o la antropología. La trashumancia ovina ha atraído especialmente a geógrafos e historiadores, existiendo una abundante bibliografía al respecto, aunque también hay estudios sobre sistemas ganaderos estantes (p. ej: García Martín, 1988; García Martín y Sánchez Benito, 1987; García Martín et al., 1991). Desde la lingüística y la dialectología nos llegan también datos de interés, aunque los atlas dirigidos por M. Alvar prestan más atención a la agricultura que a la ganadería y el pastoreo ${ }^{9}$. Al margen de los atlas, y sin entrar de lleno en la etnolingüística, hay estudios que aportan información detallada sobre terminologías y clasificaciones acerca del ganado, como ocurre con la investigación sociolingüística de Borrego Nieto (1981) sobre un pueblo sayagués.

Hasta aquí hemos hecho un repaso a algunos estudios cercanos a los intereses de la etnozoología realizados hasta finales de los años setenta, aunque alguna obra rebasa este marco. A continuación veremos la trayectoria seguida en estas investigaciones durante la última década, deteniéndonos a comentar algún trabajo concreto. Aunque no son muchos los autores que han abordado este ámbito temático, sí es posible encontrar aportaciones de gran interés. Desde quienes se sitúan a sí mismos en el marco de la antropología social, destacaremos en primer lugar los trabajos de María Cátedra sobre los vaqueiros de alzada de Asturias, en los que, como no podía ser de otra forma, la vaca recibe un tratamiento especial. No obstante, sólo uno de sus muchos artículos aborda de forma monográfica el estudio cultural de este animal, concretamente el titulado "Las vacas también son buenas para pensar. (Cátedra, 1981), con el que pretende «explorar la manera en que el grupo humano interacciona con su entorno a un nivel más elevado de la estricta base económica, en el plano mental. (ibid.: 223). El artículo aborda el análisis de las homologías existentes entre la vaca y la mujer en el mundo vaqueiro, concretamente entre vaca "roxa"-mujer vaqueira y vaca aldeana (no "roxa")-mujer aldeana; estudia también el importante papel desempeñado por dicho animal en la socialización del vaqueiro; el ciclo vital de la vaca y el elemento emocional

9 En la bibliografía citamos únicamente el Atlas Lingüístico de Andalucia, por ser el de carácter más etnográfico. 
que rodea a su muerte dentro de la casa vaqueira; y, por último, el rol desempeñado por la vaca como elemento intermediario entre vivos y muertos y su capacidad para presentir la muerte de los humanos. Este es, seguramente el estudio de mayor profundidad e interés escrito en nuestro país acerca del complejo mundo de representaciones y relaciones simbólicas que se pueden documentar entre animales y grupos humanos. La autora toma como punto de partida de su análisis una frase del libro El pensamiento salvaje de Lévi-Strauss, que "plantea la relación entre la ecología y la creatividad culturaln. En efecto, dicha obra es un auténtico hito en la corriente de investigación etnocientífica y por ello es muy acertada la referencia. Sin embargo, no estamos tan conformes con una idea previa, expuesta por el mismo autor en El totemismo en la actualidad, y que la autora también cita: "Se comprende que las especies no sean elegidas por 'buenas para comer', sino por 'buenas para pensar'. (Lévi-Strauss, 1965: 131). Este planteamiento supone llevar hasta sus últimas consecuencias, creo, una interpretación estructural-mental de la ecología que parece alejada de la realidad y que, en la práctica, M. Cátedra tampoco demuestra compartir. La autora concluye su artículo señalando que la perspectiva emic que ha planteado coincide con los intereses de la denominada "etnoecología" (no utiliza los términos etnociencia ni etnozoología), cuyo enfoque supone que el medio aprehendido, lo que percibe el grupo humano de su entorno, los significados que le añade y las clasificaciones populares de éste, pueden ser claves en la problemática ambiental y muy importantes frente a las situaciones de cambio. (Cátedra, 1981: 254). Aunque la idea es más compleja, la orientación es acertada.

Más directa y conscientemente enraizado con la etnociencia está un trabajo anterior de Joan Josep Pujadas presentado al I Congreso Español de Antropología, en 1977 (Pujadas, 1980), titulado «Sistemas de clasificación etnocientífica como una forma de adaptación ideológica. El caso del Pirineo oscense». El objetivo del autor es "analizar cómo existe una correlación directa entre las variaciones dialectales de dos comunidades y las diferentes adaptaciones técnicas, sociales e ideológicas que configuran estas diferentes microculturas". Más concretamente, tratará de "comprobar si el predominio de la actividad ganadera en Echo y la actividad agrícola en Xabierregay [las dos poblaciones estudiadas] determinan, o al menos condicionan, procesos cognitivos y perceptuales diferenciados" ( $i b i d .: 185$ ). Para cada población, se distribuye el léxico faunístico en sendos cuadros que incluyen diferentes categorías - definidas mediante claves de presencia $(+)$ y ausencia $(-)-$ como útil, doméstico, corral, casa, pesca, caza, perjudicial, mortal, cultivo, etc. La hipótesis de partida queda demostrada, 
según el autor, lo que le permite elaborar a continuación nuevas hipótesis "para el tratamiento en general de las taxonomías folk":

1) Existe una continuidad estructural entre los paradigmas léxicos y el sistema de adaptaciones culturales. De forma más general, el habla correspondiente a una unidad social determinada es un paradigma adaptado al conjunto de dimensiones que constituyen un sistema cultural.

2) Toda estructura léxica es una realidad "opaca* (subyacente e implícita) que existe más allá de las relaciones visibles por los hombres entre sí y cuyo funcionamiento constituye la lógica profunda del sistema comunicativo.

3) Todo paradigma léxico se regula homeostáticamente adecuándose a las necesidades expresivas y cognitivas del marco cultural. El paradigma léxico está, pues, en un proceso dialéctico constante con el sistema ideológico, entendido en sentido althusseriano como sistema de ideas-representaciones y como sistema de actitudes y comportamiento (Pujadas, 1980: 203).

Pujadas ha publicado otros estudios de carácter etnolingüístico centrados en el ámbito pirenaico (1973, 1976), tema al que dedicó su tesis de doctorado (1977), y ha introducido este análisis en trabajos de alcance más general (Comas y Pujadas, 1985). En todos ellos, como en el artículo comentado, el objetivo de la investigación son las taxonomías populares, que comprenden "tanto las categorías utilizadas en la clasificación, como las relaciones jerárquicas entre dichas categorías; en suma, lo que constituye la concreción de una cosmovisión (Pujadas, 1976: 152).

Íntimamente relacionada con el enfoque etnolingüístico planteado por Pujadas se encuentra la antropología cognitiva, que ya hemos comentado desde una perspectiva teórica en los primeros párrafos de este trabajo. Sin embargo, esta orientación cognitiva no ha alcanzado un desarrollo significativo en nuestro país, aunque últimamente hay cierto interés por el análisis del ‘discurso nativo* (García García, 1991), destacando asimismo las diferentes investigaciones de Buxó. Pero es precisamente en este contexto de la antropología cognitiva -aunque quizás deberíamos hablar más bien de antropología simbólica - en el que destaca de forma muy notable la obra - abundante obra ya - de Manuel Delgado, buena parte de la cual aborda el estudio de las relaciones sociedad humana-mundo animal. Delgado se mueve como pez en el agua en el terreno del simbolismo y, pese a lo discutibles que para algunos - no es nuestro caso- puedan resultar algunos de sus planteamientos, sin duda alguna debe reconocerse que sus trabajos se encuentran entre los más innovadores y gratificantes dentro del contexto de la antropología simbólica escrita en nuestro país. Sólo vamos a citar, no obstante, dos de sus trabajos que entroncan más directamente con la etnozoología. El primero es un libro publicado ya hace unos años, en 1986, con el significativo título de De la muerte de un dios, en el que se aborda de forma realmente brillante - a la par que infor- 
mativa- el inevitable mundo de la "Fiesta Nacional", de la corrida de toros. El segundo (Delgado, 1993a) es un breve artículo en el que el autor reflexiona -y sintetiza reflexiones de otros autores- sobre uno de los más tópicos y típicos objetos de estudio de la más reciente etnozoología: el auge de los animales de compañía en las ciudades.

Si de las estructuras mentales pasamos al más prosaico ámbito de la cultura material, podemos comprobar que los estudios de etnografía pastoril siguen teniendo una más que notable presencia en la bibliografía. Lo que sucede es que, exceptuando algún caso concreto, no se puede hablar de avances metodológicos. En una línea semejante a la etnografías pastoriles de las décadas anteriores se encuentran los trabajos de L. V. Elías (p. ej., Elías y Muntión, 1989), a quien también se debe la organización de unas jornadas sobre "cultura pastoril" (Elías y Grande, 1991). En esta última obra citada se encuentran ejemplos de trabajos con una orientación semejante. Un libro que debe ser destacado muy especialmente entre los que en los últimos años estudian las culturas pastoriles, es el de Severino Pallaruelo sobre los Pastores del Pirineo (1988), que combina y resuelve de forma muy satisfactoria la investigación histórica y la etnológica. Hay otros muchos trabajos de alcance local más o menos etnográficos o folklóricos, la mayoría de escasa calidad. En este ámbito localista o regionalista, debemos destacar, sin embargo, un reciente e interesante estudio sobre la ganadería y el pastoreo en el País Valenciano publicado por Frederic Martínez (Martínez y Palanca, 1991) que, por otra parte, tampoco introduce innovaciones metodológicas ni hace referencia alguna a la etnozoología o la etnociencia. No difieren mucho estos estudios de los que se autocalifican como antropología económica, aunque las investigaciones originales son escasas y en ninguna se aborda una perspectiva etnocientífica (Provansal y Molina, 1991; Sánchez Fernández, 1988, 1990). En estos últimos además, lo que en ocasiones se gana en el análisis económico, se pierde en detalle etnográfico. Por nuestra parte, hemos ensayado una aproximación, excesivamente "etnografista", a las relaciones entre ganadería, pastoreo y comunalismo en la comarca zamorana de Sayago, poniendo algún énfasis en las relaciones hombre-animal (Sánchez Gómez, 1991). Referido al mismo ámbito geográfico pero centrado en el contexto de la dehesa es un trabajo posterior en el que también se incluye información sobre la explotación económica y la interpretación cultural de diferentes especies animales.

Fuera del ámbito estricto de la antropología, pero en conexión con ella, existen algunos estudios de autores nacionales que interrelacionan ecología y cultura y que, por tanto, participan de los intereses del análisis etnocientífico, y no solamente del etnozoológico. En este caso, las apor- 
taciones de mayor interés provienen de las ciencias naturales, en concreto de los departamentos de ecología de algunas universidades, especialmente de la Autónoma de Madrid y los trabajos dirigidos desde los años setenta por Fernando González Bernáldez, fallecido en 1992. Existen muy diversas formas de abordar la ecología, y más concretamente la ecología humana, pero la orientación a la que nos estamos refiriendo es la que hace referencia a los análisis de percepción del paisaje. El objetivo es el "análisis de las preferencias paisajísticas", para lo cual

se emplean colecciones de pares de fotografías de paisajes reales, que se muestran a grupos de personas para que elijan entre las imágenes pareadas. La matriz de datos resultante de la codificación de las elecciones se analiza mediante técnicas estadísticas multivariantes con objeto de poner de manifiesto la estructura de las preferencias ante el paisaje (Ruiz, 1989: 22).

La metodología así expuesta puede resultar excesivamente mecánica, pero este análisis se completa con encuestas y recogida de documentación oral en general, de forma semejante a como se hace en el trabajo de campo etnográfico. Los resultados de esta investigación coinciden en gran parte con los que se trataría de alcanzar desde la antropología económica. Sin embargo, el análisis paisajístico tiene un evidente y consciente carácter aplicado, tanto si se realiza en medio urbano como en medio rural con problemas de degradación ecológica. En este último caso, "la base común que justifica tales estudios (...) reside en la necesidad de adecuar la gestión medioambiental y los planes de desarrollo a las necesidades concretas y percibidas como tales de las poblaciones implicadas" (Ruiz, 1989: 20). El objetivo de la obra de J. P. Ruiz de la que hemos tomado las anteriores citas es, precisamente, "contribuir a la comprensión de las relaciones entre el hombre $y$ su entorno en una zona de montaña, cuyo paisaje es el resultado de una larga interacción mutua" (ibid.: 21). Una más reciente obra de este autor, escrita en colaboración (Barrios, Fuentes y Ruiz, 1992) y titulada El saber ecológico de los ganaderos de la Sierra de Madrid, trata de acercar las visión geográfica al análisis antropológico en el estudio del medio de montaña, tomando como referente esencial el uso ganadero del espacio y las relaciones hombre-animal en general.

Como debe de haber resultado evidente, estos estudios ecológicos sobre la percepción del paisaje, desde una óptica emic, tienen una fuerte conexión con la investigación etnocientífica, y así lo hace notar el propio autor que estamos manejando al referirse a estudios sobre percepción ambiental en otras disciplinas. No obstante, el mundo animal es un elemento más de ese paisaje, no el único. Sin embargo, cuando lo que se 
estudia son sociedades ganaderas o pastoriles (como es el caso citado), el corpus nativo de conocimientos, creencias, taxonomías, etc., en relación con el ganado, se convierte en pieza capital de la investigación, y entra de lleno en el ámbito de la etnozoología ${ }^{10}$.

Si con las anteriores referencias a los estudios sobre percepción ambiental nos hemos salido del marco antropológico en sentido estricto, ahora entraremos de forma definitiva en un medio diferente: el de la zootecnia. Bajo esta denominación incluimos tanto los estudios sobre mejora de las condiciones de cría y explotación del ganado como los enfocados a la recuperación y conservación de las razas autóctonas, aunque en ocasiones ambas posiciones estén claramente enfrentadas. En realidad, la zootecnia que nos interesa -y que interesa a la antropologíaes aquella que estudia la explotación del ganado en sistemas de pastoreo o en regímenes extensivos, no en los de carácter industrial. Todo ello teniendo en cuenta que en nuestro país no se ha desarrollado una verdadera corriente de estudios etnozootécnicos, como en el caso francés, que, pese a las limitaciones que señalaba Digard (ver supra), resulta de un enorme interés.

Por lo anteriormente dicho, la investigación zootécnica -o de orientación afín - que vamos a citar, es la que afecta a la explotación de razas autóctonas, especialmente de ganado ovino y vacuno. Dentro de este conjunto de estudios, podemos establecer al menos tres grandes apartados: 1) catálogos de razas de ganado (Sánchez Belda, 1981 y 1984; Sánchez B. y Sánchez T., 1986; Esteban y Tejón, 1986; García, Martínez y Orozco, 1990); 2) descripciones particulares de razas locales (Echeverría, 1975; Miguel, 1977-78 y 1981-82; Sánchez García, 1978; Francia, 1978; Sánchez Belda, 1983; vVAA, 1991); y 3) análisis de explotación de ecosistemas locales a partir de razas autóctonas (Montserrat y Fillat, 1977-78; García Dory, 1980; Fillat et al., 1988; García Dory y Martínez, 1988; García Ruiz y Lasanta-Martínez, 1989).

En los catálogos encontramos detalladas descripciones de razas autóctonas y extranjeras integradas, con referencias no sólo a las aptitudes y características del ganado, sino a los sistemas de explotación tradicionales y modernos, léxico ganadero, etc. Además, en las obras de Sánchez Belda se incluyen también extensos apartados de carácter histórico, donde se estudian las transformaciones habidas en técnicas de cría, pastoreo y aprovechamiento económico de los animales. Esta misma información es la que ofrecen los estudios monográficos sobre razas autóctonas citados

10 Sobre el tema de la percepción del paisaje pueden consultarse diferentes artículos de ecólogos y geógrafos en el número 6 (julio-septiembre, 1993) de la revista Ecosistemas. 
en segundo lugar, aunque, obviamente, con mayor profundidad y detalle que en los catálogos. Por último, los estudios sobre utilización de razas autóctonas en ecosistemas regionales -que tienen a M. A. García Dory como principal representante- son aún de mayor interés para el etnólogo, pues su objetivo es potenciar la cría en pureza - con cruces primarios industriales- de dichas razas en sistemas extensivos, en los que las técnicas tradicionales de pastoreo son fundamentales.

Antes de concluir estos comentarios sobre disciplinas y estudios cercanos a la etnozoología, conviene hacer referencia a dos ámbitos muy especializados que acaparan una importante bibliografía que puede ser de alguna utilidad a la investigación etnozoológica. Nos referimos a la caza y la lidia. Las diferentes actividades cinegéticas han generado multitud de relatos sobre monterías, batidas, armas, animales de presa, espacios de caza, etc. Son escasos, sin embargo, los estudios históricos y, sobre todo, sociológicos o antropológicos que abordan una interpretación disciplinar de esa actividad (Grande del Brío, 1982), algo que en Francia, por ejemplo, alcanza cierto desarrollo en los últimos años. No obstante, lo que sí está avanzando de alguna manera dentro de nuestras fronteras son los estudios sobre economía y geografía de la caza, como queda patente en el reciente número monográfico sobre "La caza en España" de la revista Agricultura y Sociedad (núm. 58, 1991) y en las Actas del VI Coloquio de Geografia Rural (Madrid: Universidad Autónoma, 1991).

En cuanto a la lidia, existe un condicionante casi insuperable para una interpretación mínimamente objetiva del hecho: la opinión favorable o contraria a los festejos taurinos, posición inicial que suele ser determinante de las investigaciones. Por otra parte, aunque la bibliografía sobre el mundo de los toros es enorme, no abundan los estudios antropológicos sobre la lidia en concreto o sobre cualquier tipo de fiesta en la que intervengan toros o vaquillas. Hay descripciones etnográficas más o menos folklóricas, alguna incursión histórico-cultural (Caro Baroja, 1984) y trabajos antropológicos, algunos de ellos muy controvertidos, como los de PittRivers (1984, 1986, 1989, 1993) o el más asequible de Mira (1976) sobre - fiestas de toros de carácter popular. Como ya se ha mencionado en otro lugar, la aproximación antropólogica española más destacada a estas celebraciones, más concretamente a la corrida de toros, es la realizada por Manuel Delgado (1986). No obstante, también en el contexto de la antropología simbólica destacan de forma muy notable los trabajos de Ginés Serrán Pagán, publicados hace ya algunos años ${ }^{11}$. Un primer artículo

11 Hay que recordar, por otro lado, la frontal oposición que mantenía Serrán Pagán con respecto a las interpretaciones sostenidas por Pitt-Rivers, tanto acerca del mundo taurino en particular como con respecto al estudio antropológico de Grazalema. 
(Serrán Pagán, 1977) plantea un interesante acercamiento general al ritual del toro en España, con alguna referencia más detallada a las celebraciones de Grazalema. Precisamente sobre las celebraciones del toro en este pueblo gaditano trata un artículo publicado en 1979, tema que se amplía y compara con las festividades taurinas de Pamplona en un libro editado en castellano en 1981, que apareció un año antes en inglés. La obra de Serrán, a diferencia de la de Delgado, asume una perspectiva más amplia en el análisis del ritual del toro, relacionándolo de forma especial con el contexto social y económico en el que se produce y transforma, insistiendo siempre en la necesidad de unir los análisis histórico y antropológico. Además de las obras de los autores españoles citados, también se ha publicado en castellano un interesante artículo del antropólogo francés $F$. Saumade (1992), estudioso de la cultura tauromáquica camarguesa ${ }^{12}$, en el que realiza un estudio comparativo de la cría del toro de lidia en esta comarca francesa y en la Baja Andalucía.

No obstante, son los análisis históricos los que se llevan la palma en cuanto al número de publicaciones sobre la lidia, siendo buena muestra el estudio histórico-folklórico de L. Ortiz-Cañavate (1931) y especialmente el famoso y enciclopédico “Cossío. De los once volúmenes publicados, el primero resulta especialmente interesante desde una perspectiva etnozoológica, en concreto los estudios sobre "El toro en la zoología", "El ganado bravo en el campo", "Clases de fiestas de toros", y "Al margen de la lidia. Lo mismo ocurre con el extenso trabajo incluido en el tomo XI sobre "La cría y selección del toro de lidia en la actualidad., escrito por Álvaro Domecq y Díez. Finalmente, la lidia también ha generado estudios de carácter zootécnico -como el que acabamos de citar-, o simplemente descriptivo, que pueden resultar de interés por la información relativa a las peculiares técnicas de cría y explotación de este ganado bravo (Purroy, 1988; Barga, 1989; López del Ramo, 1991).

Sobre las celebraciones que tienen como protagonista al toro, sin ceñirse exclusivamente a la lidia, los trabajos de mayor alcance y erudición son los ya clásicos estudios de Álvarez de Miranda. Nos referimos a su artículo de 1954 sobre "Magia y religión del toro norteafricano* y muy especialmente a su libro Ritos y juegos del toro, de 1962. Contamos, además, con estudios sobre rituales específicos, como el famoso artículo de Caro Baroja (1944-45) sobre el toro de San Marcos. o el más antiguo y breve de S. Múgica (1920) sobre •Bueyes y carneros en los entierros", tema

12 Este mismo autor ha publicado recientemente un libro en el que estudia por extenso las culturas tauromáquicas de Camarga y Andalucía, obra que no hemos podido consultar (Saumade, 1994). 
este último que también abordaron puntualmente algunos otros folkloristas vascos del momento.

Pero el mundo del toro no es el único que ha llamado la atención de los investigadores. Por ejemplo, son especialmente famosas, y han sido bien estudiadas, las carreras de gallos (Caro Baroja, 1983: 75-90; Díaz Viana, 1982). Apenas hay bibliografía acerca de las competiciones de animales (luchas de gallos, carreras de galgos y caballos, etc.), su papel en espectáculos circenses o, finalmente, sobre el fenómeno de los animales de compañía. Deliberadamente, dejamos fuera de este repaso otros ámbitos de investigación sobre el mundo animal, como la etología o la arqueozoología, escasamente desarrollados en nuestro país. No obstante, en el caso concreto de la etología de los primates tenemos dentro de nuestras fronteras una de las figuras más respetadas internacionalmente: J. Sabater Pi. También en arqueozoología (o zooarqueología) se hacen trabajos interesantes en algunos departamentos de arqueología y zoología de distintas universidades españolas.

En resumen, y por lo que al ámbito español se refiere, es bien notorio que sólo muy parcialmente podemos hablar de la existencia de investigaciones etnozoológicas; es más, en toda la bibliografía consultada —que no es exhaustiva, ni mucho menos- apenas aparece mencionado este término. Sin embargo, hemos visto que existen numerosos estudios que conectan con los intereses de la etnozoología, pero que se quedan cortos en su alcance. Son mayoritarios los de orientación folklorista, en los que aparece contemplado parcialmente el ámbito de las representaciones mentales relacionadas con el mundo animal, pero casi siempre con una simple intención documental. Por otra parte, comprobamos que continúa gozando de cierto vigor la investigación etnográfica sobre culturas pastoriles, pero aquí el avance metodológico es prácticamente nulo. Este empuje podría llegar de las antropologías económica y ecológica, pero su desarrollo es muy limitado dentro de nuestras fronteras. Por su parte, el interés de algunos autores, como Delgado, por el simbolismo si ha permitido la elaboración de obras de interés. El problema es que no parece existir línea alguna de investigación salvo la que marca el interés personal de uno u otro autor. En conclusión, queda bastante camino por andar en la investigación etnozoológica española.

\section{LUIS ÁNGEL SÁNCHEZ GÓMEZ \\ Dpto. de Prehistoria y Etnología Universidad Complutense Madrid}




\section{BIBLIOGRAFIA}

ALBERT-LlORCA, MARLÉNE, 1991: L'ordre des choses. Les récits d'origine des animaux et des plantes en Europe, Paris: Comité des Travaux Historiques et Scientifiques.

- 1993: "Les récits d'origine européens: l'étiologie sans le mythe?", Ethnologie française, 23-1, 66-73.

AlVAR, M., y LloRENTE, A., 1961-1973: Atlas lingüistico y etnográfico de Andalucia. Sevilla: Universidad de Granada/CSIC, 6 vols.

Álvarez DE Miranda, A., 1954: "Magia y religión del toro norteafricano", Archivo Espanol de Arqueologia, XXVII, 3-44.

- 1962: Ritos y juegos del toro, Madrid: Taurus.

Álvarez OBlanCA, W., 1986: "La matanza del cerdo", Libro de la gastronomía de Castilla y León, Valladolid: Junta de Castilla y León, 103-117.

AMADES, JOAN, 1932: "Vocabulari dels pastors". Butlleti de Dialectologia Catalana, XIX, 207 pp.

- 1933: El llenguatge de les bèsties $i$ de les coses, Barcelona: La Neotípia.

- 1952: "El mito de la fiera malvada", RDTP, VIII, 117-143.

- 1962: :El testamento de animales en la tradición catalana", Ibid, XVIII, 339-394.

- 1988: L'origine des bêtes (Petite cosmogonie catalane), Carcassonne: Garae-Hésiode [orig. 1950].

APPlebaum, HeRBer, 1987: "Structural and Cognitive Anthropology. Introduction", en H. Applebaum (ed.), Perspectives in Cultural Antbropology, Albany: State University of New York Press, 401-410.

Barandiarán, J. M. DE y MANTEROla, A. (dirs.), 1990: la alimentación doméstica en Vasconia, Bilbao: Eusko Jaurlaritza, Etniker Euskalerria, 159-194.

Barrau, Jacques, 1981: "La etnobiología”, en R. Cresswell y M. Godelier, Útiles de encuesta y de análisis antropológicos, Madrid: Fundamentos, 81-92.

- 1985: "A propos du concept d'ethnoscience", Les savoirs naturalistes populaires. Actes du séminaire de Sommnières, 12 et 13 décembre 1983, Paris: Ed. de la Maison des sciences de l'homme, 5-12.

- 1988: :Ethnosciences", Encyclopaedia Universalis, Paris: Encyclopaedia Universalis, Corpus 7, 482-484.

BarRios, J. C.; Fuentes, M. ${ }^{a}$ T. y RUIZ, J. P., 1992: El saber ecológico de los ganaderos de la Sierra de Madrid, Madrid: Agencia de Medio Ambiente de la Comunidad de Madrid.

BALCHE: SFrie, 1988: "L'homme et l'animal", Encyclopaedia Universalis, Paris: Encyclopaedia Universalis, Corpus 2, 173-176.

Berte-FriedBerg, C., 1991: "Ethnoscience", en P. BONTE y M. IZARD, Dictionnaire de l'ethnologie et de l'anthropologie, Paris: Presses Universitaires de France, 252-255.

BorREgo NiETO, Julio, 1981: Sociolingüística rural. Investigación en Villadepera de Sayago, Salamanca: Universidad de Salamanca.

BouISSAC, P., 1972: .Perspectives ethnozoologiques: le statut symbolique de l'animal au cirque et au zoo", Ethnologie française, 3-4, 287-294.

BOUZA BreY, FERmín, 1949: :El lagarto en la tradición popular gallega", RDTP, V, 531-550.

BROMBERGER, CHRISTIAN, 1986: :Les savoirs des autres-, Terrain. Carnets du patrimonie ethnologique (Les hommes et le milieu naturel), 6, 3-5. 
Bueno, GuSTAvo, 1990: Nosotros y ellos. Ensayo de reconstrucción de la distinción emic/ etic de Pike, Oviedo: Pentalfa.

BUXO, M. JEsús, 1980: “Antropología Cognitiva y Ecología Biocultural. Notas sobre el concepto de adaptación, I Congreso Español de Antropología. Actas, Barcelona: Universidad de Barcelona, I, 299-318.

Calvo I Calvo, lluis, 1990: Catàleg de materials etnogràfics de l'Arxiu d'Etnografia $i$ Folklore de Catalunya, Barcelona: CSIC.

Caro Baroja, Julio, 1944-45: "El toro de San Marcos", RDTP, I, 88-121.

- 1983: El carnaval (Análisis histórico-cultural), Madrid: Taurus [orig. 1965].

- 1984: “Toros y hombres... sin toreros", Revista de Occidente, 36, 7-26.

CASAS, NICOLÁS, 1844-1849: Biblioteca completa del ganadero y agricultor, Madrid: Imp. Calleja, 7 vols.

- 1857: Diccionario manual de agricultura y ganadería españolas, Madrid: Calleja, López y Rivadeneyra eds., 4 vols.

CASTAÑó, LUCIANO, 1972: "Apuntes folklóricos sobre la vaca en Asturias", RDTP, XXVIII, 291-315.

CÁtEDRA TOMÁs, MARí, 1981: "Las vacas también son buenas para pensar", Revista de Estudios Agro-Sociales, 116, 219-254.

CAZA, 1991: "La - en España", Agricultura y Sociedad, 58 [número monográfico].

Clifford, J. y MARCus, G. E., 1991: Retóricas de la antropologia, Madrid-Gijón: Júcar [orig. 1986].

Cluton-Brock, Juliet (ed.), 1989: The Walking Larder. Patterns of domestication, pastoralism, and predation, London: Unwin Hyman.

- 1994: .The unnatural world. Behavioural aspects of humans and animals in the process of domestication, en A. MANNING y J. SERPELl (eds.), Animals and buman society. Changing perspectives, London/New York: Routledge, 23-35.

COFRAdiA EXTREMEÑA DE GASTRONOMfa, 1991: La matanza en Extremadura, Mérida: Editora Regional de Extremadura.

Comas D'ARgemir, D. y Pujadas, J. J., 1985: Aladradas y güellas. Trabajo, sociedad y cultura en el Pirineo aragonés, Barcelona: Anthropos.

CORTÉs VÁZquez, Luis, 1952: "Ganadería y pastoreo en Berrocal de Huebra (SalamanCa), RDTP, VIII, 425-464 y 563-595.

- 1957: Las ovejas y la lana en Lumbrales (Pastoreo e industria primitiva en un pueblo salmantino), Salamanca: Centro de Estudios Salmantinos.

Cossfo, José Marfa, 1980: Los toros. Tratado técnico e bistórico. Tomo I, Madrid: EspasaCalpe [orig. 1943].

COSTA, JOAQuín (dir.), 1981a: Derecho consuetudinario y economía popular de España, Zaragoza: Guara Ed. [orig. 1902].

- 1981b: "Concejo colectivista de Sayago", en J. Costa (dir.) (1981a), II, 21-47 [orig. 1902].

- 1983: Colectivismo agrario en España, Zaragoza: Guara Ed., Instituto de Estudios Agrarios, Pesqueros y Alimentarios, 2 vols. [orig. 1898].

Danés I TORRas, D. y Carreras I ARTau, J., 1990: QQuestionari núm. 4. Primer sobre ética i dret consuetudinaris i economia popular de Catalunya. Costums i tractes més usuals referents a bestiar, en Ll. Calvo i Calvo (1990), 51-54 [orig. 1918].

Delgado Ruiz, Manuel, 1986: De la muerte de un dios. La fiesta de los toros en el universo simbólico de la cultura popular, Barcelona: Península.

- 1993a: .El síndrome del domador. Algunas claves culturales del auge de los animales en la ciudad., Claves, 31, 34-40. 
- 1993b: "La pasión administrada. Tauromaquia y castidad en la literatura puritana inglesa del xvilr, Fundamentos de Antropologia, 2, 58-65.

Díaz Viana, LuIs, 1982: "El juego de los gallos (Formas, textos e interpretaciones)., Revista de Folklore, 24, 183-191.

DIGARD, JEAN-PIERRE, 1990: L'bomme et les animaux domestiques Antbropologie d'une passion, Paris: Fayard.

DOMECQ y Díez, Álvaro, 1985: El toro bravo. Teoria y práctica de la bravura, Madrid: Espasa-Calpe.

- 1989: "La cría y selección del toro de lidia en la actualidad, en A. DOMECQ Y DfEz. y J. J. DE Bonifaz, Los toros. Tratado técnico e bistórico. Tomo XI. Apéndice 19781988, Madrid: Espasa-Calpe, 11-304.

ECHEVERRÍA BELZUNEGUI, TEÓFILO, 1977: Raza vacuna pirenaica. Evolución, situación actual y perspectivas, Pamplona: Diputación Foral de Navarra.

Elias Pastor, L. V. y GRande Ibarra, J. (coords.), 1991: Sobre cultura pastoril, Sorzano (La Rioja): Centro de Investigación y Animación Etnográfica/Instituto de Restauración y Conservación de Bienes Culturales.

- y Muntión HeRnáez, C., 1989: Los pastores de Cameros, Logroño: Gobierno de la Rioja/Ministerio de Agricultura, Pesca y Alimentación.

EstebAN MUNOZZ, C. y TEJÓN TEJÓN, D., 1986: Catálogo de razas autóctonas españolas. I. Especies ovina y caprina, Madrid: Ministerio de Agricultura, Pesca y Alimentación (2. ${ }^{2}$ ed.).

FIDAlgo SANTAMARIÑA, JOSÉ ANTONIO, 1985: "Ganado porcino: modalidad de existencia y papel en el seno de una comunidad rural de Galicia., Trabalhos de Antropologia e Etnologia, 25 (2-4), 297-325.

Fillat, FEDERICO, et al., 1988: “Sistemas ganaderos de montaña", Agricultura y Sociedad, 46, 119-190.

Fowler, Catherine S., 1979: "Etnoecología", en DONAld L. HaRdesty, Antropología ecológica, Barcelona: Bellaterra, 215-238.

FRANCIA, IGNACIO, 1978: La raza morucha, Salamanca: Mataderos del Oeste, S. A.

GARCía DORY, Miguel ÁNGEl, 1980: "La utilización de las razas autóctonas en los ecosistemas regionales, como factor de ahorro energético en la ganadería española-, Agricultura y Sociedad, 15, 115-161.

- y MARTINEZ VICENTE, S., 1988: La ganadería en España, Madrid: Alianza.

-, Martínez Vicente, S. y Orozco Piñán, F., 1990: Guía de campo de las razas autóctonas de España, Madrid: Alianza.

Garcia Garcia, J. L., 1991: ¿Qué tienen que ver los españoles con lo que los antropólogos saben de ellos?., en M. CátEDRA (ed.), Los españoles vistos por los antropólogos, Madrid-Gijón: Júcar, 109-126.

GARCIA MARTIN, PEDRO, 1988: La ganadería mesteña en la España borbónica, Madrid: Ministerio de Agricultura.

- y SÁNCHEZ BENITO, J. M.² (comps.), 1987: Contribuciones para una bistoria de la trasbumancia en España, Madrid: Ministerio de Agricultura.

- et al., 1991: Cañadas, cordeles y veredas, Valladolid: Junta de Castilla y León.

Garcia-Ruiz, J. M. y Lasanta-MaRTinez, T., 1989: :La ganadería extensiva en áreas montañosas marginales: algunos problemas teóricos y prácticos", Anales del Instituto de Estudios Agropecuarios, XI, 77-94. 
GOMIS, CELS, 1910: Zoologia popular catalana. Modismes, aforismes, creencies, supersticions, etc., etc. que sobre'ls animals bi ba a Catalunya, ab gran nombre de confrotacions, Barcelona: Tip. :L'Avenç".

GOODENOUGH, WARD C., 1974: "Análisis componencial, en D. L. Sills (dir.), Enciclopedia Internacional de las Ciencias Sociales, Madrid: Aguilar, 1, 231-236 [orig. 1968].

GrANDE Del BRío, RAMÓN, 1982: Socioecología de la caza, Madrid: Istmo.

- 1984: El lobo ibérico. Biología y mitología, Madrid: Hermann Blume.

GUICHOT Y SIERRA, ALEJANDRO, 1922: Noticia bistórica del Folklore. Orígenes en todos los países hasta 1890. Desarrollo en España hasta 1921, Sevilla: Hijos de G. Álvarez.

HAudricourT, A.-G. y L. HÉDIN, 1987: L'Homme et les plantes cultivées, Paris: A.-M. Métailié lorig. 1943].

HeAdland, T. N.; PIKE, K. L. y HARRIS, M. (eds.), 1990: Emics and Etics. The Insider/ Outsider Debate, Newbury Park, California: Sage Pub.

INGOLD, TIM, 1986: The appropriation of nature. Essays on buman ecology and social relations, Manchester: Manchester University Press.

- 1988: Hunters, pastoralists and ranchers. Reindeer economies and their transformations, Cambridge: Cambridge University Press [orig. 1980].

- 1994: "From trust to domination. An alternative history of human-animal relations", en A. Manning y J. Serpell (eds.)., Animals and buman society. Changing perspectives, London/New York: Routledge, 1-22.

- (ed.), 1987: What is an Animal?, London: Unwin Hyman.

KavanNaG, WILliam, 1994: Villagers of the Sierra de Gredos. Transhumant cattle-raisers in central Spain.

LÉvi-STRAuss, Claude, 1965: El totemismo en la actualidad, México: Fondo de Cultura Económica [orig. 1962].

- 1982: El pensamiento salvaje, México: Fondo de Cultura Económica [orig. 1962].

LOPEZ Del RAMO, JOAQuin, 1991: Por las rutas del toro. Geografía europea del toro de lidia, Madrid: Espasa-Calpe.

LOPEZ LINAGE, JAVIER, 1978: Antropologia de la ferocidad cotidiana: supervivencia y trabajo en una comunidad cántabra, Madrid: Ministerio de Agricultura.

MACHAdo y NúÑEZ, ANTONIO, 1882-83: "El Folk-Lore del perro", El Folk-Lore Andaluz, 24-29 y 68 bis-75 bis.

MANSO PEREZ, M.' ISABEL, 1990: "La matanza y el mondongo en la provincia de Zamora", en Universidad y Etnologia. V Encuentro en Castilla y León (Alimentación tradicional), Salamanca: Centro de Cultura Tradicional, Diputación de Salamanca, 351-363.

MARTINEZ, FREDERIC y PALANCA, FloReAl, 1991: Utillatge agrícola y ramaderia, Valencia: Institució Valenciana d'Estudis i Investigació.

Miguel PAlomino, ÁNGel DE, 1977-78: ‘Pasado y presente de las razas vacunas santanderinas de montaña. Selección de textos y comentarios*, Anales del Instituto de Estudios Agropecuarios, III, 9-63.

- 1981-82: :La raza vacuna pasiega", ibid., V, 9-64.

MirA, JOAN F., 1976: "Toros en el Norte valenciano: notas para un análisis", en C. LISÓN Tolosana (ed.), Temas de Antropología Española, Madrid: Akal, 107-129.

MONTSERRAT ReCORDER, P. y Fillat ESTAQUE, F., 1977-78: .La ganadería extensiva y las culturas rurales montañesas", Anales del Instituto de Estudios Agropecuarios, III, 83-120.

MORPHY, HOWARD, 1989: Animals into art, London: Unwin Hyman.

MÚGICA, SERAPIO, 1920: "Bueyes y carneros en los entierros", Revista Internacional de los Estudios Vascos, XI, 100-105. 
Ortiz-CAÑAVATE, LORENZO, 1931: “El toreo español, en F. CARreras CANDI (dir.), Folklore y costumbres de España, Barcelona: Casa Editorial Alberto Martín, I, $377-569$.

Pallaruelo, Severino, 1988: Pastores del Pirineo, Madrid: Ministerio de Cultura.

PitT-Rivers, Julian, 1984: "El sacrificio del toro", Revista de Occidente, 36, 27-47.

- 1986: "Fiestas populares de toros", en L. Díaz VIANA (coord.), Etnología $y$ folklore en Castilla y León, Salamanca: Junta de Castilla y León, 97-107.

- 1989: "Las Fiestas Taurinas en Extremadura", en J. Marcos Arévalo y S. Rodriguez BECERRA (coords.), Antropología cultural en Extremadura, Mérida: Asamblea de Extremadura, Ed. Regional de Extremadura, 225-227.

- 1993: "Taurolatrías. La Santa Verónica y los toros", Fundamentos de Antropología, 2, 67-74.

PRATS, LloRENÇ, s. f.: "L'estudi històric de les formes de vida populars a la Catalunya contemporània (segle XIX), Simposi d'antropologia cultural sobre Xavier Fäbregas, Publicacions de l'Abadia de Montserrat (sep.).

Prieto, LAUREANO, 1949: “Notas etnográficas sobre animales domésticos y salvajes de La Gudiña (Orense)", Douro-Litoral, 3. ${ }^{2}$ serie, V, 50-67.

- 1953: "La zoantropía en Galicia", Zepbyrus, IV, 353-362.

Provansal, Danielle y Molina, Pedro (eds.), 1991: Etnologia de Andalucia Oriental. I. Parentesco, agricultura y pesca, Barcelona: Anthropos/Instituto de Estudios Almerienses.

PujADAS, JOAN JOSEP, 1973: “Etnolingüística del valle de Bielsa. Aproximación a una etnolingüística general del Alto Aragón", Ethnica, 6, 181-234.

- 1976: "Ensayo etnolingüístico: el campo léxico de las denominaciones orográficas", Ethnica, 11, 149-177.

- 1977: Aspectos etnolingüisticos del Alto Aragón (tesis de doctorado), Barcelona: Universidad de Barcelona.

- 1980: "Sistemas de clasificación etnocientífica como una forma de adaptación ideológica. El caso del Pirineo oscensen, I Congreso Español de Antropología. Actas, Barcelona: Universidad de Barcelona, I, 181-216.

Pujol, RAYMOND, 1988: "A propos d'ethnozoologie", Terrain. Camets du patrimonie etbnologique (Des hommes et des bêtes), 10, 108-111.

- y Carbone, Geneviève, 1991: "L'homme et l'animal, en Jean Polrier (dir.), Histoire des moeurs I. Les coordonnées de l'bomme et la culture matérielle, Saint-Georges-deLuzençon: Gallimard, 1306-1388.

PuRROY UNANUA, ANTONIO, 1988: La cria del toro bravo. Arte y progreso, Madrid: MundiPrensa.

RUIZ SANZ, JUAN P., 1989: Ecología y cultura en la ganaderia de montaña. Percepción y gestión del ecosistema pastoril por los ganaderos de la Sierra de Madrid, Madrid: Ministerio de Agricultura, Pesca y Alimentación.

SÁNCHEZ BELDA, ANTONIO, 1981: Catálogo de razas autóctonas españolas. II. Especie bovina, Madrid: Ministerio de Agricultura, Pesca y Alimentación.

- 1983: La raza bovina avileña-negra ibérica, Madrid: Ministerio de Agricultura, Pesca y Alimentación.

- 1984: Razas bovinas españolas, Madrid: Ministerio de Agricultura, Pesca y Alimentación.

- y Sánchez Trujlllano, M. C., 1986: Razas ovinas españolas, Madrid: Ministerio de Agricultura, Pesca y Alimentación ( $2 .^{2}$ ed., corregida y aumentada). 
SÁNCHEZ FERNÁNDEZ, J. O., 1988: “Estrategias económicas entre los vaqueiros de alzada del concejo de Somiedo (Asturias)", Boletín del Instituto de Estudios Asturianos, 125, 189-213.

- 1990: .Toma de decisiones en la cría de ganado vacuno entre los vaqueiros de alzada del Puerto de Somiedo (Asturias),, Agricultura y Sociedad, 55, 167-198.

SÁNCHEZ GARCí, LUCIANO, 1978: Raza vacuna rubia gallega. Evolución, situación actual y perspectivas zootécnicas, Lugo: Asociación Nacional de Criadores de Ganado Vacuno Selecto de Raza Rubia Gallega.

SÁNCHEZ GÓMEZ, L. A., 1991: Sayago. Ganadería y comunalismo agropastoril, Zamora: Caja España.

SANTOS, Teresa de y SANZ, IgnaCio, 1988: La matanza del puerco, Valladolid: Centro Etnográfico de Documentación, Diputación de Valladolid.

SAUmADE, Fréderic, 1992: "La crianza del toro de lidia entre Baja Andalucía y Camarga: de la oposición técnica al sistema semántico", Historia y fuente oral, 8, 63-73.

- 1994: Des sauvages en Occident. Les cultures tauromachiques en Camargue et en Andalousie, Paris: Éd. de la Maison de sciences de l'homme.

Serrán PaGÁn, G., 1977: "El ritual del toro en España. Algunos errores de análisis y método", Revista de Estudios Sociales, 20, 87-99.

- 1979: .El toro de la Virgen y la industria textil de Grazalema. Transformación económica y cambios en el mundo simbólico de un pueblo andaluz", Revista Española de Investigaciones Sociológicas, 5, 119-135.

-1981: Pamplona-Grazalema. De la plaza pública a la plaza de toros, Barcelona: Instituto de Estudios Norteamericanos.

SIGAUT, Franç̧oIs, 1978: "Un tableau des productions animales", Journale d'Agriculture et de Botanique Appliquées, XXV, 2, 119-123.

- 1979: :Les savoirs relatifs aux animaux domestiques, leur rôle historique et technologiquen, Ethnozzotechnie, 20, 16-22.

- 1988: "Critique de la notion de domestication", L'Homme, 108, 59-71.

SPERBER, DAN, 1975: "Pourquoi les animaux parfaits, les hybrides et les montres sont-ils bons a penser symboliquement?, L'Homme, XV-2, 5-34.

Sturtevant, Whliam C., 1964: ‘Studies in Ethnoscience,, American Anthropologist, 66 (3), 99-131.

TABOADA, Jesús, 1969: ‘La matanza del cerdo en Galicia», RDTP, XXV, 89-105.

TESTART, A., 1987: "Deux modèles du rapport entre l'homme et l'animal dans les systèmes de représentations", Études rurales, 107-108, 171-193.

THÉRET, MARCEL, 1988: “Zootechnie,, Encyclopaedia Universalis, Paris: Encyclopaedia Universalis, Corpus 18, 1252-1256.

URfA RIU, JUAN, 1976: Los vaqueiros de alzada y otros estudios (De caza y etnografía), Oviedo: Biblioteca Popular Asturiana.

VIOLANT I SIMORRA, RAMON, 1953: "Los animales de color negro en las supersticiones españolas:, RDTP, IX, 272-328.

- 1958: .Posible origen y significado de los principales motivos decorativos y de los signos de propiedad usados por los pastores pirenaicos", ibid., XIV, 78-163.

- 1979a: "El cultiu tradicional de les abelles al Pallars Sobirà", Obra oberta, Barcelona: Altafulla, I, 51-85 [orig. 1935].

- 1979b: .Costums de la cria i de la matança del porc al Pallars Sobirà, ibid., III, 11 36 [orig. 1935]. 
- 1979c: «El nom, les habituds, les funcions biològiques i les malalties de les ovelles, al Pallars Sobirá. Notes lingüistico-folklòriques", ibid., IV, 73-90 [orig. 1954].

VV. AA., 1975: L'bomme et l'animal. Premier colloque d'etbnozoologie, Paris: Institut international d'éthnosciencies.

VV. AA., 1985: Les savoirs naturalistes populaires. Actes du séminaire de Sommières 12 et 13 décembre 1983, Paris: Editions de la Maison des sciences de l'homme.

VV. AA., 1988a: Homme, animal, société I. Biologie et animal, Toulouse: Presses de l'Institut d'Études Politiques.

VV. AA., 1988b: Homme, animal, société II. Droit et animal, Toulouse: Presses de l'Institut d'Études Politiques.

VV. AA., 1989: Homme, animal, société III. Histoire et animal, Toulouse: Presses de l'Institut d'Études Politiques, 2 vols.

VV. AA., 1991: La raza cburra en Castilla y León, Valladolid: Junta de Castilla y León.

WILLIS, RoY G., 1990: Signifying Animals. Human Meanings in the Natural World, London: Unwin Hyman.

Se presentan las diferentes interpretaciones propuestas en el campo internacional y durante las últimas décadas sobre la etnozoología, así como la relación que ha mantenido y mantiene con otros ámbitos de la antropología. También se hace un repaso de los estudios publicados en España desde finales del siglo pasado y relacionados de alguna manera con la etnozoología, desde el ámbito del folklore hasta la antropología simbólica, pasando por los estudios de etnografía pastoril.

In this paper a survey is made of the different interpretations of ethnozoology, outlined in the international scientific context during the last decades. Also a study is presented of the relations of ethnozoology with other divisions of anthropology, as well as a review of the Spanish studies related in some way with this matter -in the fields of folklore, pastoralist etnography and simbolic anthropology- written from the end of the XIXth century onwards. 